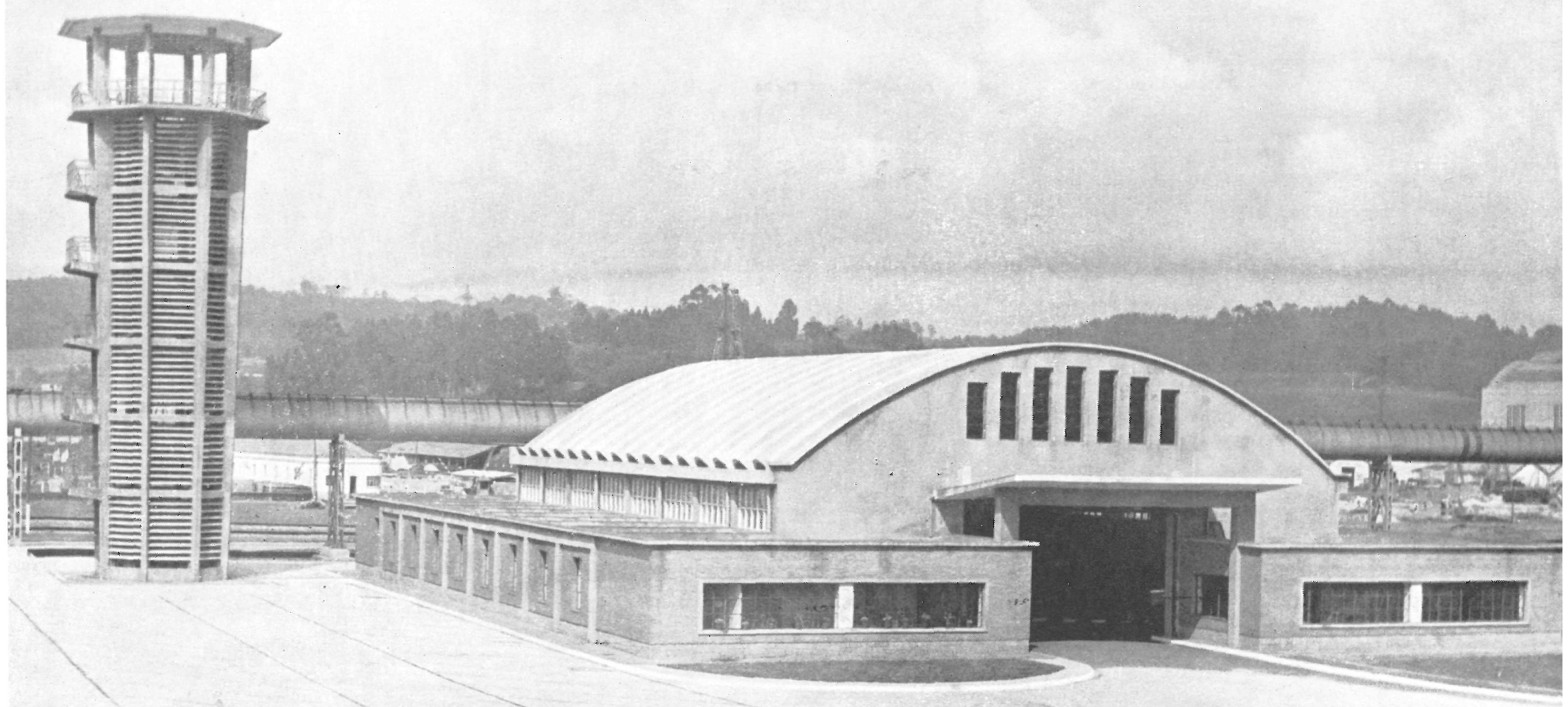

$132-28$

\title{
servicios generales
}

Junto a los edificios estrictamente industriales, en los que se materializa y concreta un rígido programa de fabricación, existen otra serie de edificios destinados a servicios generales, en los que ya las imposiciones funcionales no son de orden tan riguroso. Por ello, en el conjunto de edificios que albergan estos servicios generales de la Factoría de Avilés existe una mayor variedad, pero sin apartarse de la tónica general del conjunto, fiel a la sencillez y austeridad que rige la composición de las diversas construcciones.

\section{servicio contra incendios}

El parque de bomberos se aloja en un edificio de planta rectangular, cubierto con bóveda cerámica ondulada, y destacándose de él la torre exenta, destinada al secado de las mangas, que constituye el acento vertical del conjunto.

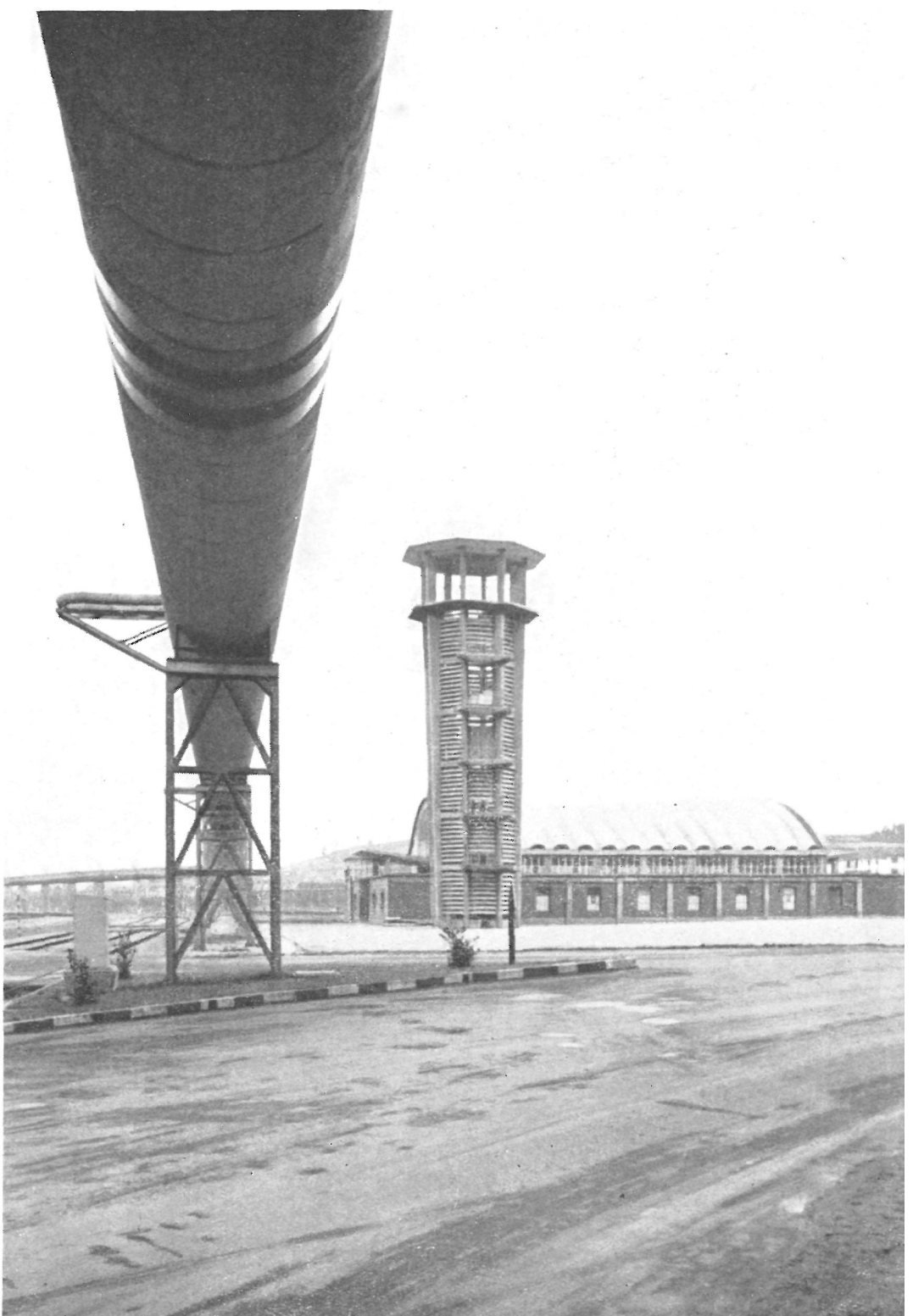




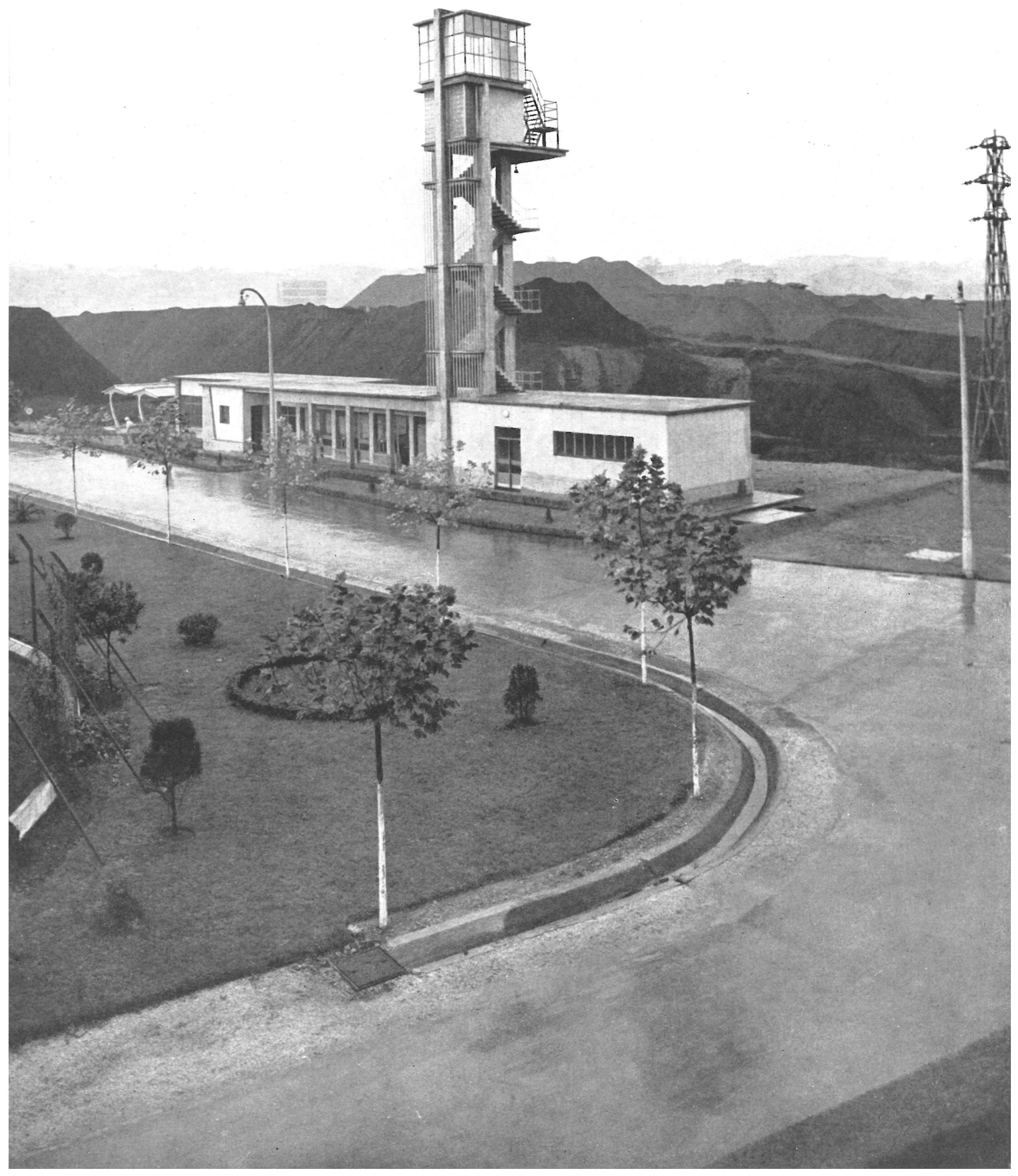




\section{puestos de enclavamiento}

Para la protección del tráfico ferroviario y de los cruces a nivel con las carreteras del servicio interior de la Factoría, se ha desarrollado un sistema de enclavamiento y señalización eléctrica. Cuatro puestos de mandos principales, distribuídos en los puntos neurálgicos de la red ferroviaria, ordenarán el tráfico, de forma autónoma, dentro de sus respectivas zonas de influencia, estando subordinados para la circulación de paso al puesto número 1 , situado en la estación de clasificación.






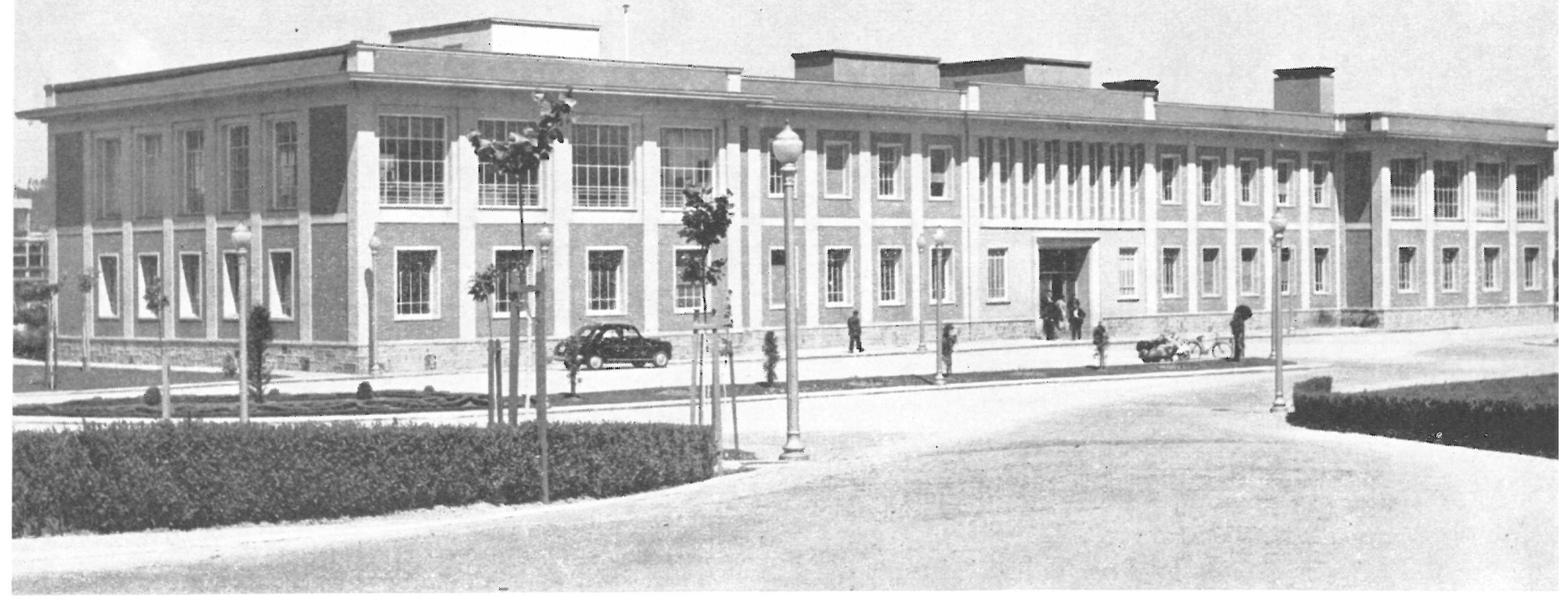

\section{laboratorio}

Este edificio, de dos plantas y sótano (superficie total $3.100 \mathrm{~m}^{2}$ ), con estructura de hormigón armado, aloja los distintos laboratorios que controlan la cantidad de la producción siderúrgica y los que durante la época de construcción de la Factoría vigilaron constantemente la calidad de los materiales empleados, con un rigurosísimo control.

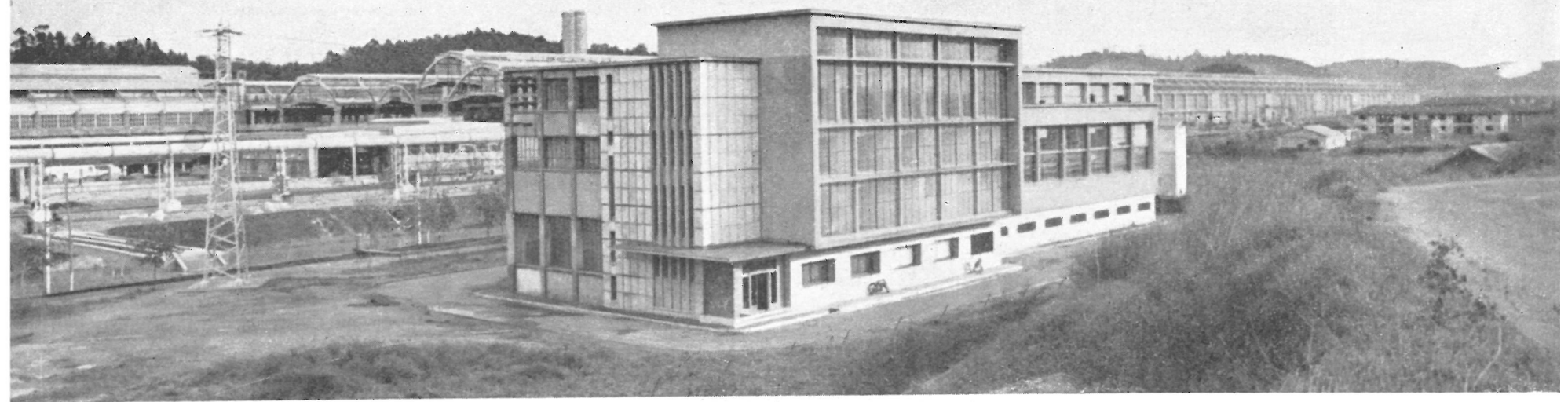

\section{subestación de laminación}

Una más de las que, distribuídas en los puntos clave del consumo, reducen la tensión del transporte, de $\mathbf{5 0 . 0 0 0} \mathrm{V}$, a tensiones de utilización. De la importancia del consumo de energía en Laminación, puede dar idea el tamaño de este edificio. 


\section{oficina \\ de hornos de acero}

Este edificio aloja los servicios técnicos de la acerería Siemens. En él se ha dispuesto también un pequeño laboratorio que controla, de forma inmediata, la calidad del acero mediante el continuo analisis de los hornos.

\section{garaje}

Tiene una superficie total de $5.800 \mathrm{~m}^{2}$. Alo ja también las oficinas y servicios propión de la organizapor carretera.

Lleva anejo un edificio destinado a taller de reparaciones de vehículos, dotado de toda la maquinaria precisa para este fin.

\section{taller eléctrico}

Este edificio, destinado a la reparación del material eléctrico de la Factoría, está constituído por cinco naves paralelas $y$ un adosado para oficinas y servicios, perpendicular a ellas. La nave situada más al Norte tiene dos plantas y está destinada a almacén. Las cua tro restantes constitu yen el Taller y tienen mas de $12 \mathrm{~m}$, excepto la central, con $14 \mathrm{~m}$. Todas están servidas por puentes-grúa.
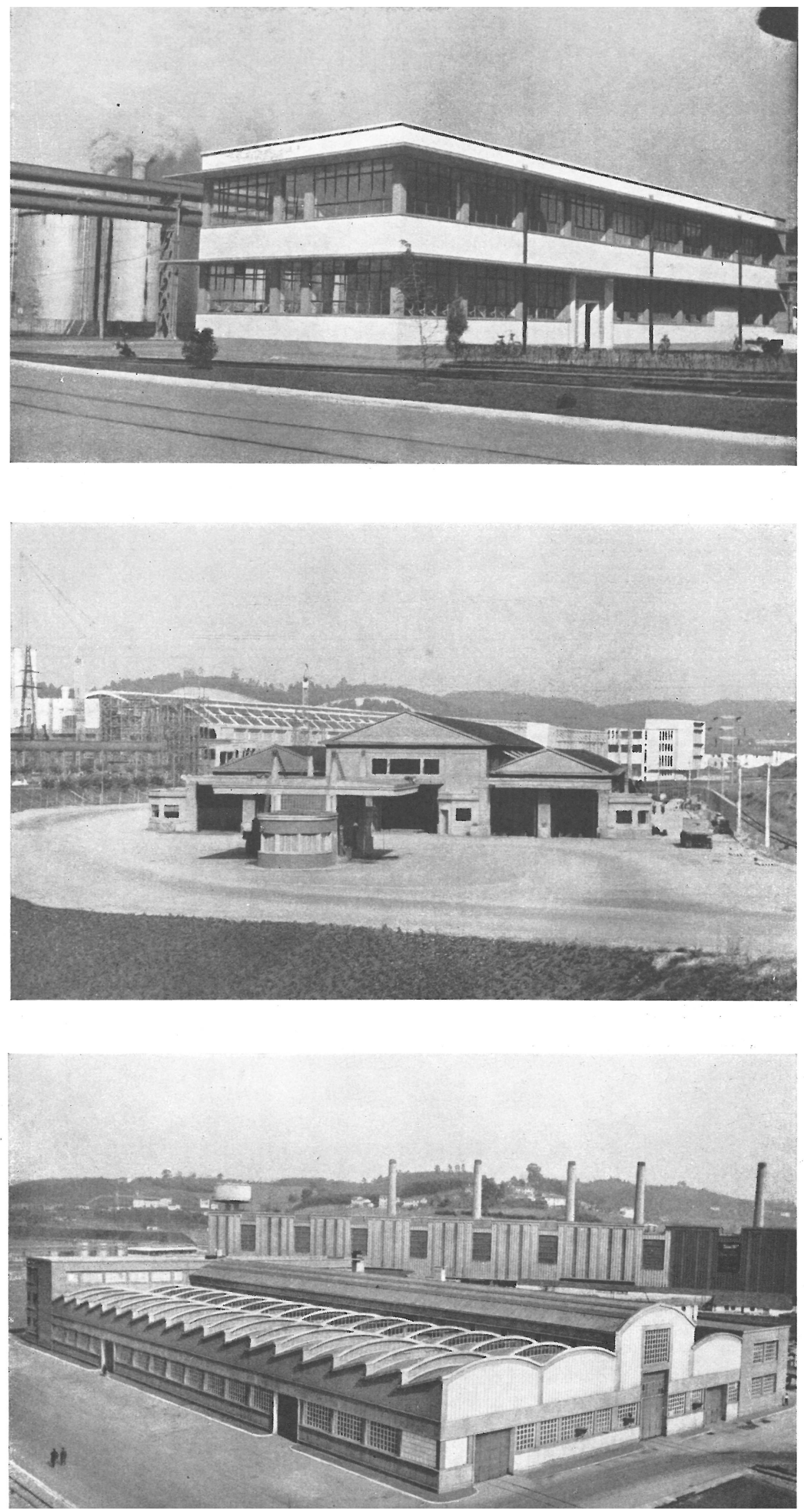


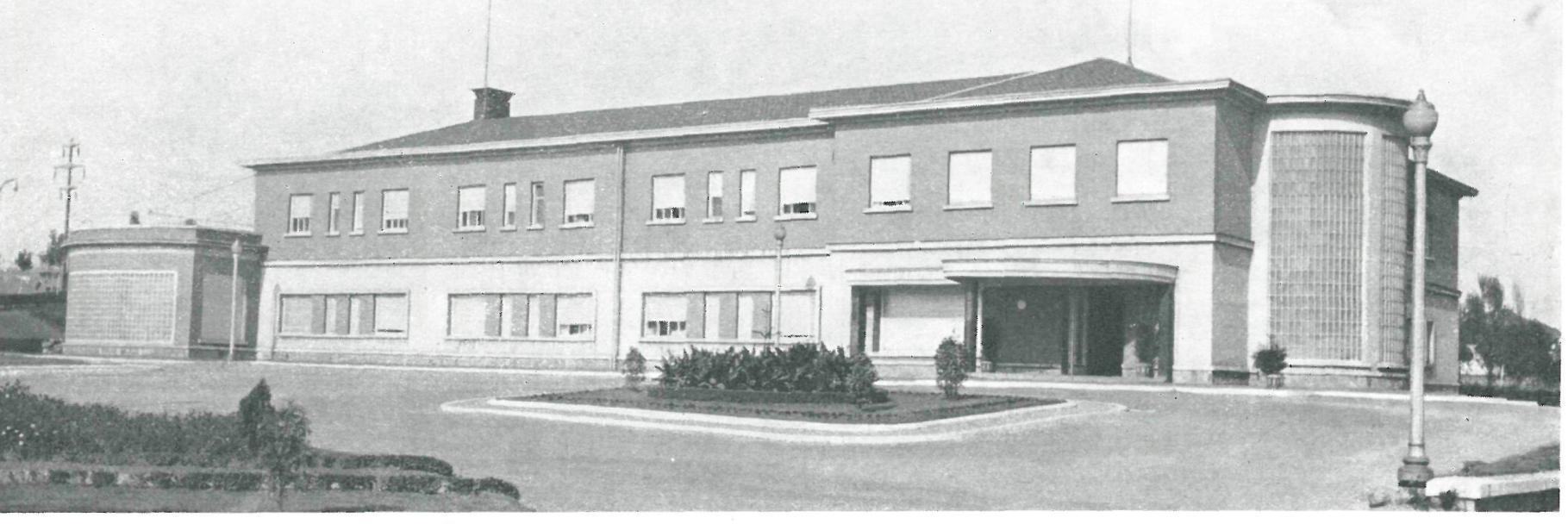

\section{planta baja}

1. Quirófano.-2. Aseo Médicos.-3. Entrada.-4. Yesos.-5. Cámara oscura.-6. Rayos X.-7. Depósito.-8. Camillas.-9. Baño.-10. Esterilizacion.-11. Despacho Medico.-12. Habitación Medico.-13. Habitación Practicante. 14. J armacia. y reconocimiento.-23. Aseos.-24. Entrada servicios.-25. Cabina.
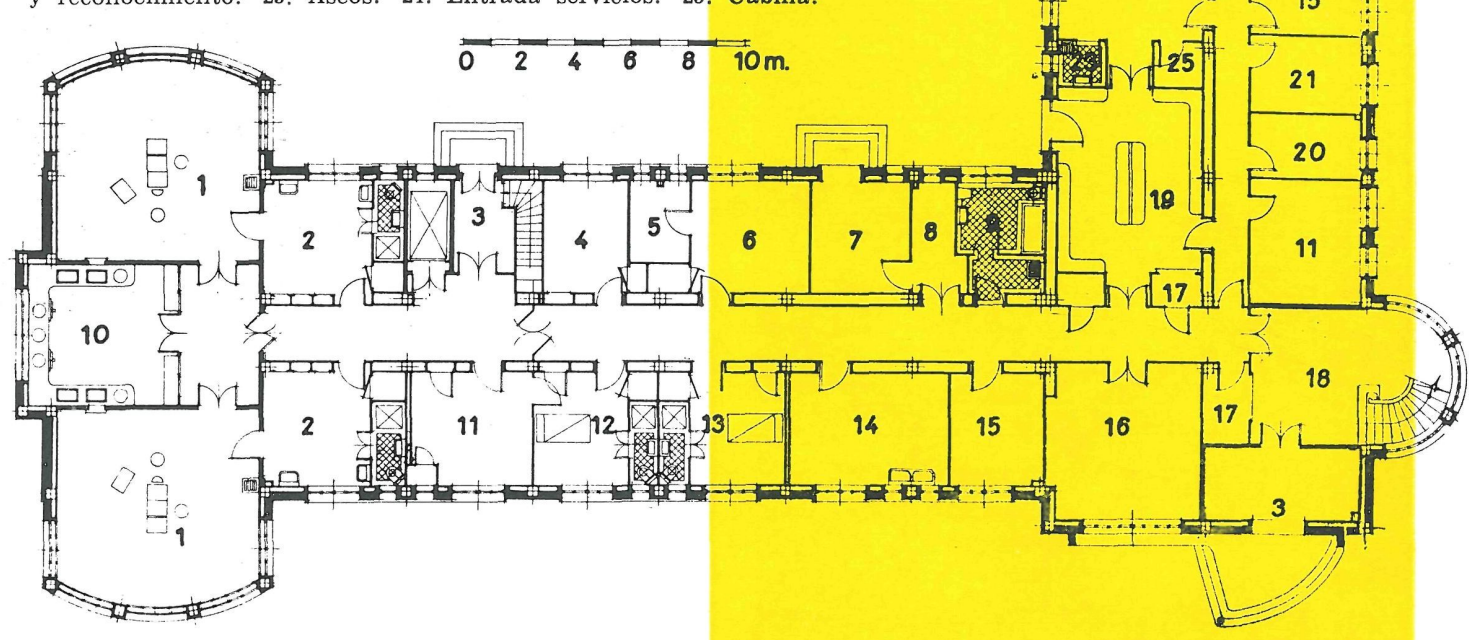

\section{planta primera}

1. Vestíbulo.-2. Visitas.-3. Estar.-4. Comedor--5. Ropero-6. Armarios.-7. Plancha.-8. Enfermero.-9. Servicio.-

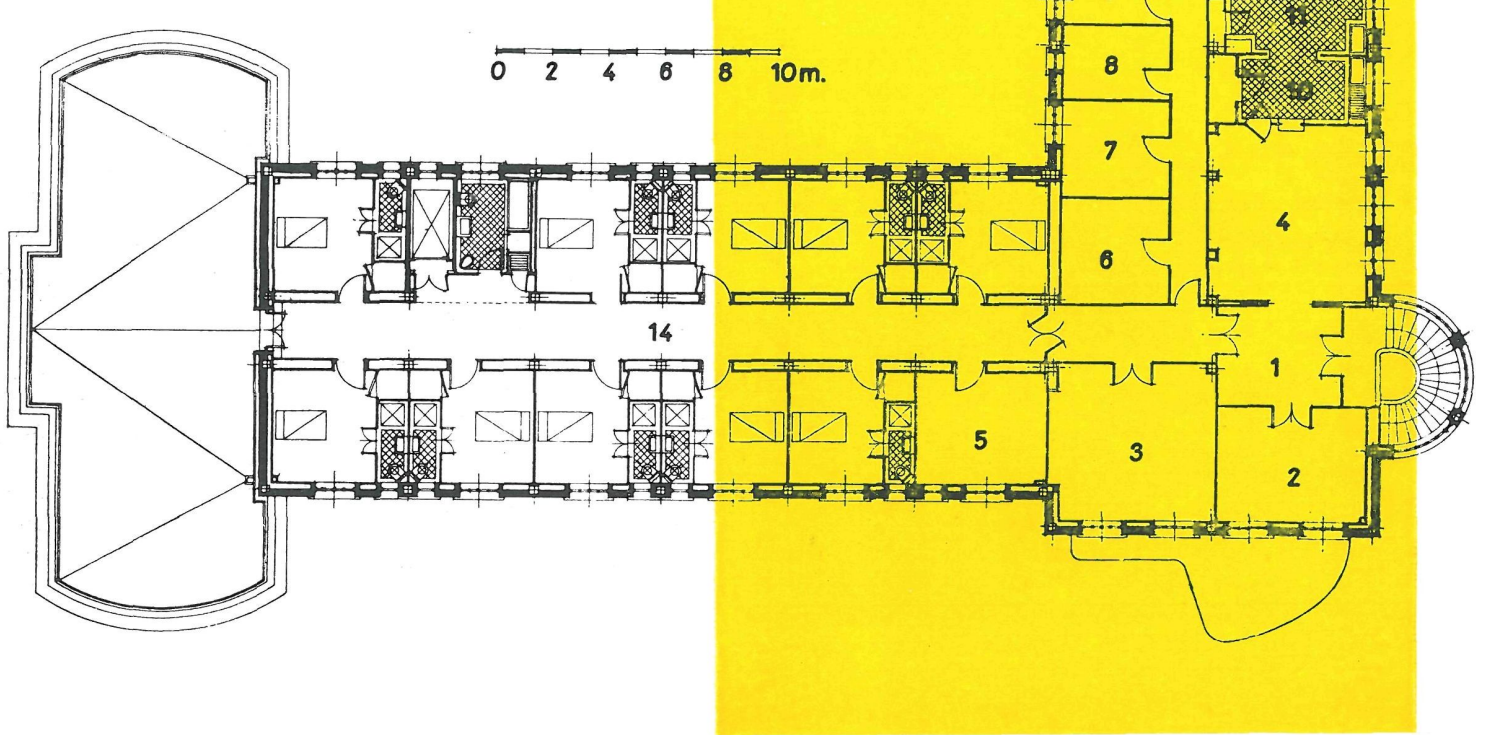

Dotado de modernas instalaciones atiende todos los servicios sanitarios de la Factoría, contando para ello con una completa dotación de personal sanitario en servicio permanente. 


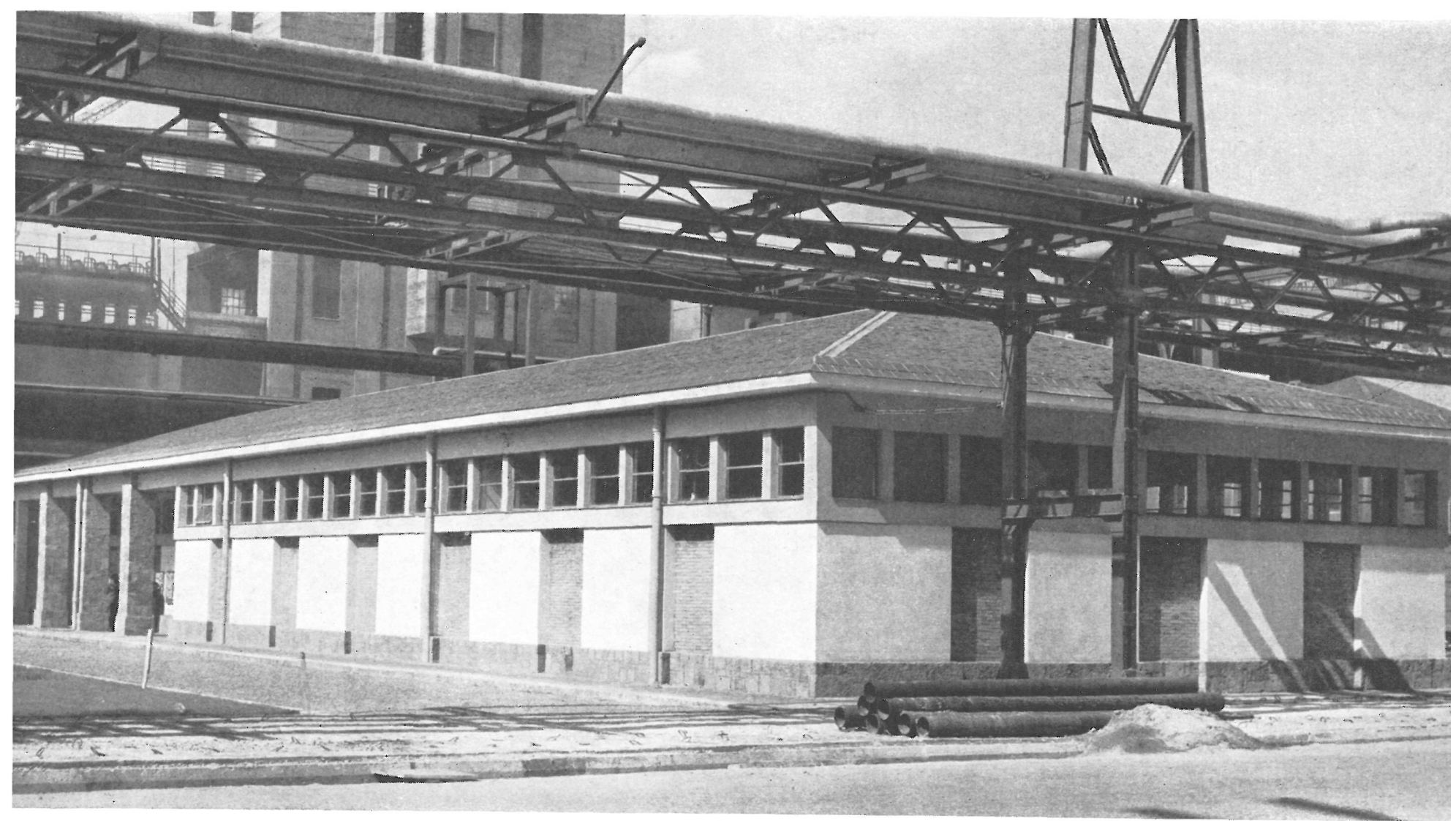

\section{servicios}

para el personal de central térmica y de baterías de cok

En cada centro de producción e han previsto locales que alojan los servicios para el personal: duchas, vestuarios, armarios para la ropa, come dores, etc.

También se ha dispuesto en ellos los servicios de listería y control de entrada y salida al trabajo.

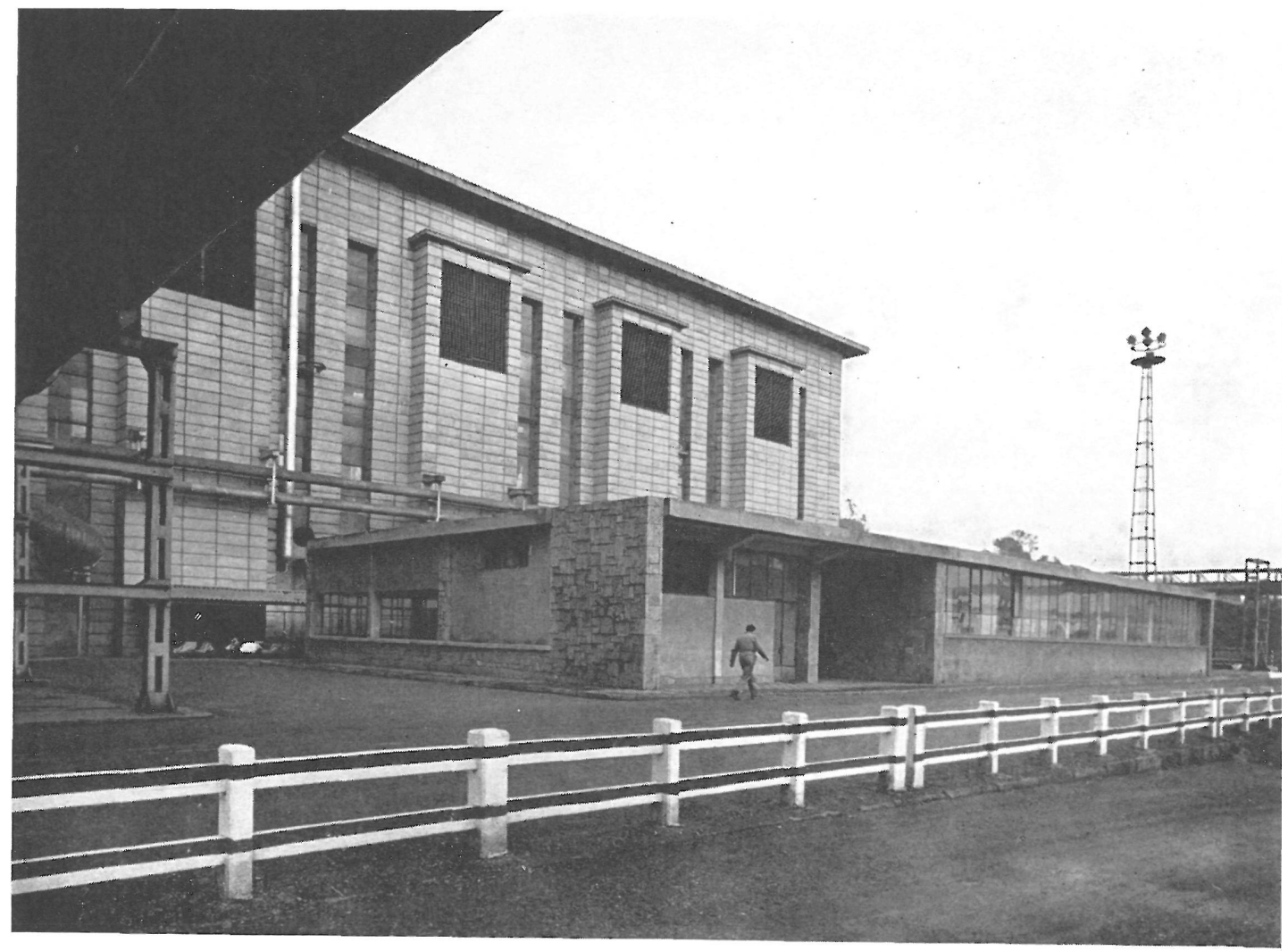



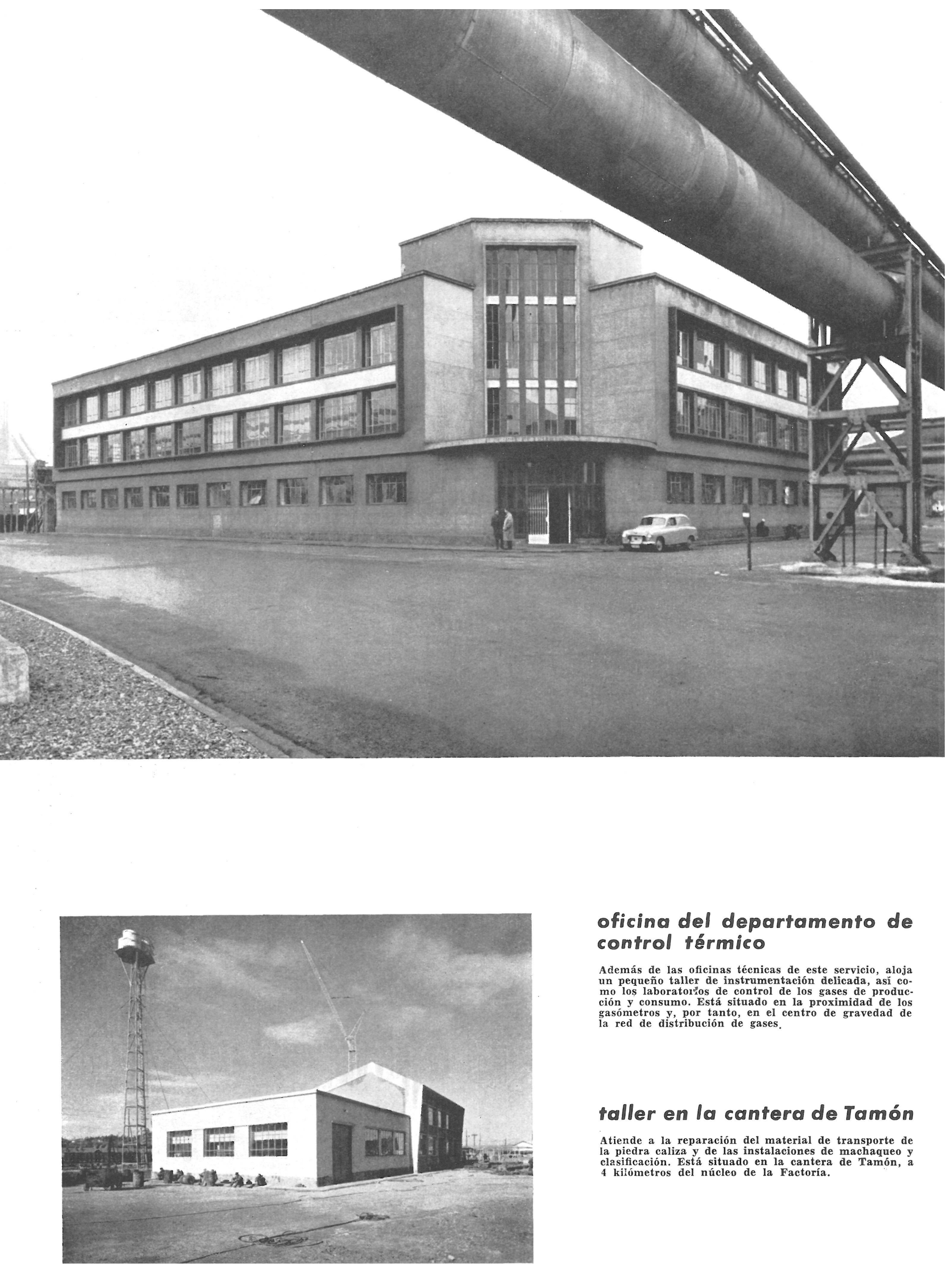

oficina del departamento de control térmico

Además de las oficinas técnicas de este servicio, aloja un pequeño taller de instrumentación delicada, así como los laboratoros de control de los gases de producción y consumo. Está situado en la proximidad de los la red de distribución de gases.

\section{taller en la cantera de Tamón}

Atiende a la reparación del material de transporte de la piedra caliza y de las instalaciones de machaqueo y clasificación. Está situado en la cantera de Tamón, a 


\section{depósito \\ de locomotoras}

Consta de dos naves adosadas, cubiertas con cerchas inclinadas que facilitan la disposición de lucernarios verticales. Tiene una superficie total de $2.400 \mathrm{~m}^{2}$ y dispone de un adosado con un pequeño taller, oficina y servicios sociales para el personal.

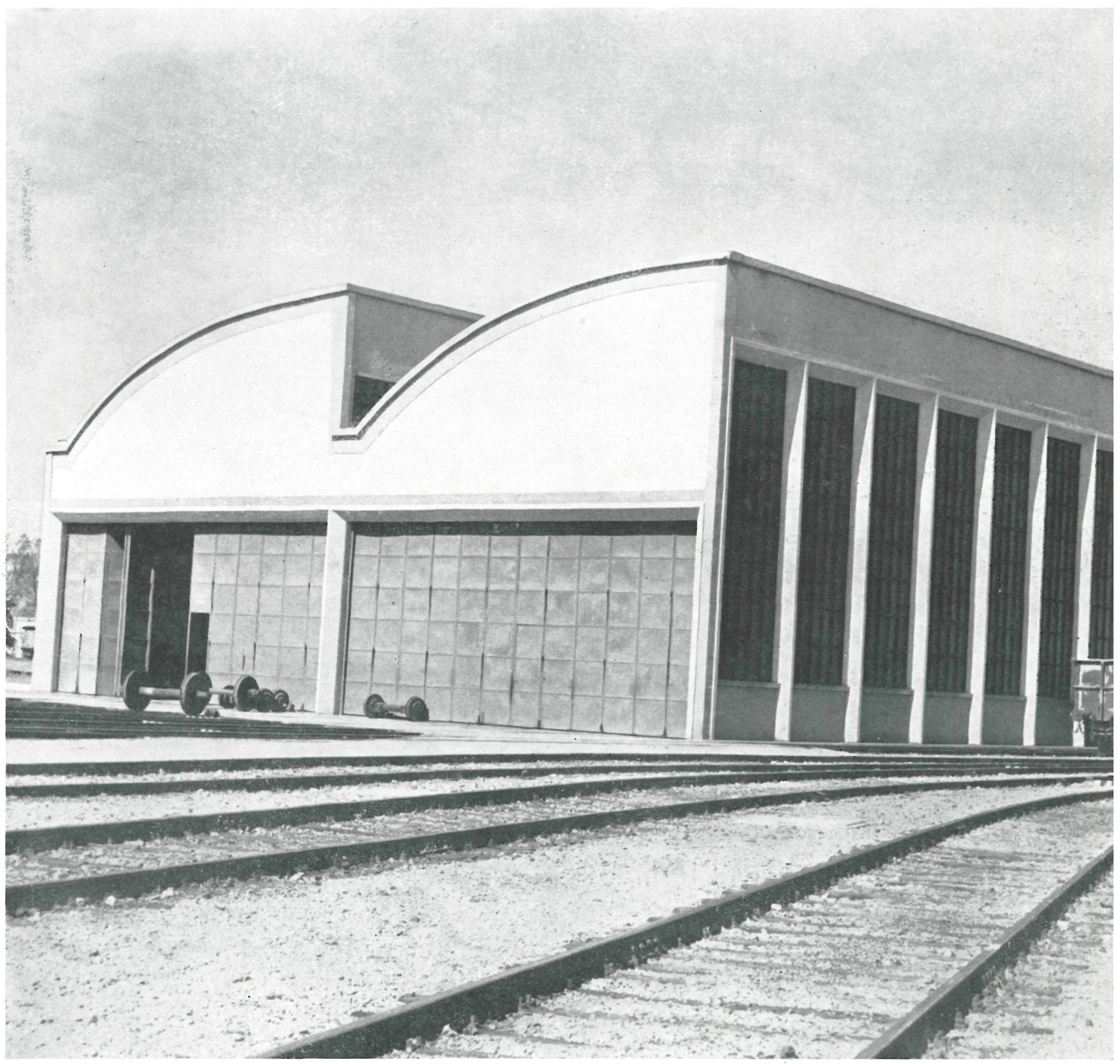




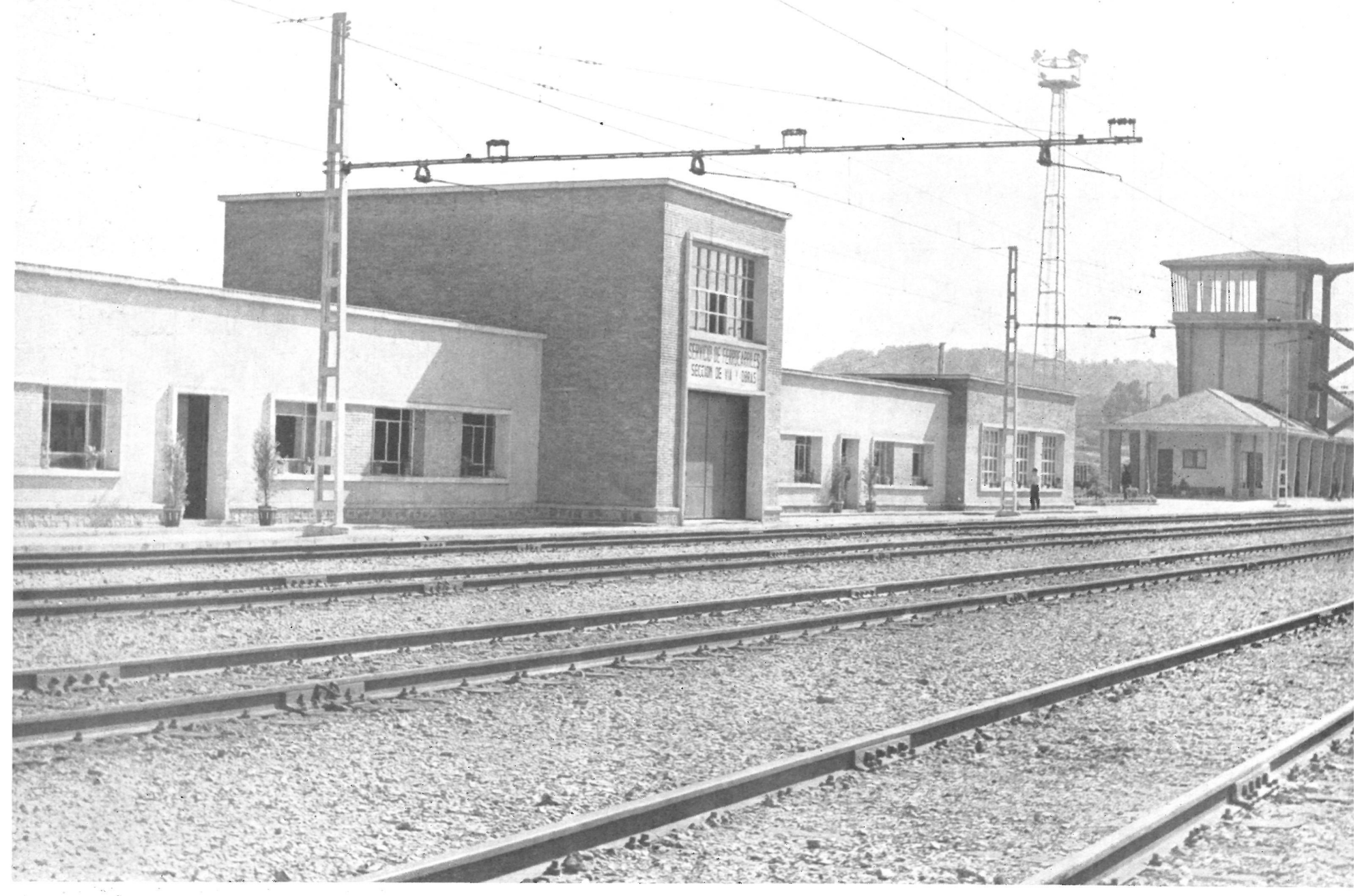

\section{estación de clasificación}

Cuenta con un edificio central donde estân instalados los despachos del jefe de estación,

vía y obras y enclavamientos.

En una torre se ha instalado la cabina del puesto de mando central

de las instalaciones de enclavamiento y señalización.

Otro edificio recoge los talleres

y almacenes

de material ferroviario.

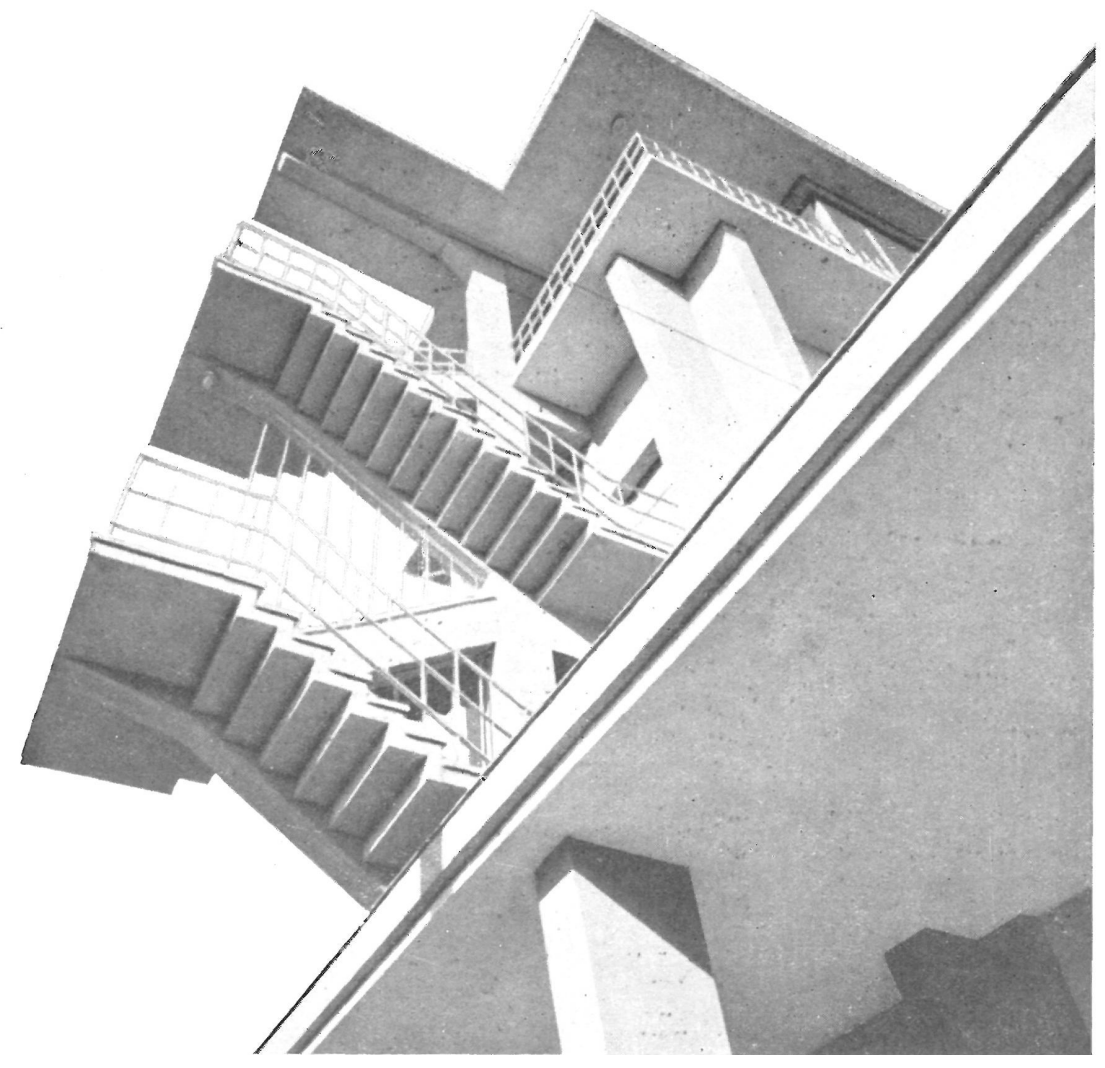

